\title{
Michel Serres' multidisciplinary philosophy of information and knowledge
}

\author{
SDE BEER ${ }^{1}$
}

\begin{abstract}
This paper is a tribute to the formidable multidisciplinary philosophy of information of the French philosopher, Michel Serres. His approach is to an extent based on his statement: "Let us nevertheless try to see on a grand scale, to enjoy a multiple, and by times connective, intellection". His main focus is on the notion of intellection which can be related to human spirituality, perception, understanding and comprehension. This human quality is urgently required if we want to reflect on knowledge as a multiple phenomenon. His view of knowledge differs in a substantial way from currently held views on knowledge and information and hence his plea: Let the new knowledge come. The human quality of intellection is equally important when it is realised that the phenomenon of knowledge in its multiplicity can only be properly grasped when viewed from the perspective of the extensive transdisciplinary connectiveness between knowledges, which creates room for what can significantly be called the world-mapping of knowledge and which strongly suggests the spatial character of knowledge and information. Thanks to the quality and capacity of intellection it becomes possible to demonstrate certain deeply theoretical and immensely practical issues in the embracement of the idea of a new conception of knowledge.
\end{abstract}

Keywords: Intellection, connectivity,multiplicity, new knowledge, invention

\section{Introduction}

When Michel Serres (1989a: 177) wrote: 'Let the new knowledge come', it was almost as if he was expressing it as a prayer. It sounds like a great expectation on the one hand, and like a sigh of discontent with regard to its opposite, let us call it 'old knowledge', on the other hand. Is this really the case? Are we operating with old knowledge, inappropriate knowledge and inadequate knowledge? Is the hope for new knowledge a realistic hope, a futile exercise, or already a reality? Too many scientific discourses suggest the last option to be the case. What are the limitations of the old knowledge and the possibilities of the new knowledge? Under what theoretical and methodological conditions can we expect knowledge, old or new, to emerge? It is fairly clear that they require different conditions; different in terms of assumptions, methods, and modes of thinking.

This article argues in favour of this other fully legitimate level of activity and motivation which must deliberately be put outside the field of operations and operational research. The terms operation and operationalisation are representative of the empiricist approach to

1. Prof. Fanie de Beer is attached to the Department of Information Science, University of Pretoria, Pretoria. 
research, its verification principle, and method of verification and measurement and define scientific concepts solely with a focus on those experimental procedures that can be used to establish their applicability from where and in terms of which the prominence of applied sciences in contemporary scientific work emerges. The implications, fairly sterile and unproductive, are suggested by the following questions: Is scientific work justifiable in any other terms or along any other routes than the one of problem formulation and potential solutions? Is this the only route and why, in case it is? Is the so-called problem not enormously inhibiting, limiting, done in terms of personal interests, prescriptive, and prejudicial? Who is anyhow able to formulate a problem outside these restrictions? Anyone who drops the shackles of the dogmatic image of thought. This image of thought clings to problems, methods and solutions. We have to move beyond the level of the dogmatic and onto the level of the valuable in order to achieve an understanding of alternative ways of pursuing knowledge and doing science than the traditionally accepted ways, ways of value, insight, wisdom and invention. In this regard the following three publications are of immense importance: Between time and eternity: the new place of the human being in natural science (Prigogine \& Stengers 1989); The uncertain quest: science, technology, and development (Salomon, et al. 1994) and Thinking science or the issues of knowledge (D'Espagnat 1990). It seems clear that much more room should be made for thoughtful free reflection on what is given, which may eventually prove to be certainly a much more fruitful and rewarding exercise and practice. In this case not method but a 'beyond method', not solution but invention, and not a problem but a situation is required. Value is brought into the picture and so is freedom. It is of decisive importance to realise the limitations of this operationalistic approach and that alternatives, although denied by many, are real possibilities according to many others. The latest book by Isabelle Stengers, Une autre science est possible! (2013) (Another science is possible!), is one of the most important recent confirmations of the possibility of an alternative way, and most probably more fruitful way of doing science.

The objectives of research is not as simple as merely solving a problem. It is much more and much rather a matter of taking care of the future of our profession of library and information science and work and of future knowledge workers in the sense of the expansion of these acivities in the past decades in order to include all knowledge domains and all knowledge activities. This article is prepared with this context in mind. It remains with us who are actively involved in the profession to work out a space, not only for ourselves, but for the wider community of knowledge workers as well. And this caretaking is, moreover, not merely a matter of keeping a profession going and moving forward, but of making society going and moving forward. No progress of a kind can be expected without a comprehensive understanding of knowledge as well as of knowledge work in terms of a new and different idiom.

In order to facilitate this new approach to science and knowledge for the information professionals (that would certainly benefit the wider group of knowledge workers as well) we have to take a close look at the main requirements for an information professional regarding the knowledge issue in particular. Mason (1990) offers excellent guidelines in this respect. He writes: 'Information professionals possess specialized knowledge about knowledge itself which they use to improve the intellectual state of people. Information professionals empower their clients to understand and to know. ... This empowering information... consists of the signs and symbols that one mind uses to influence another mind... . Information professionals are the people who carry out this process of influence on the mind. To be more precise, information professionals are mediators between one mind ... and another mind...' (Mason 
1990: 123-124). This approach gives depth, suppleness, variety, substance and practicality, room for movement and invention, to our profession. The development of the disposition suggested here will be in compliance with the dynamics of the field of information and knowledge work and use. What is meant by dynamics of the field? At least that no rigid or inflexible approach would be able to deal with this dynamics. In a more positive tone it has to be emphasized that flexibility and suppleness in thinking and an accommodating spirit with reference to the multiple viewpoints we encounter in this dynamic field can help us to move forward in a substantial and inventive way.

During the past decades developments in every area important for information science, information practice and information and knowledge work were fast and vast. Institutionalized terms, conceptions and views, pertaining to our field became outdated. Terms such as knowledge, information, human subjectivity, users, language, reading and writing, transmission, organization and retrieval, and management, to mention only a few, have been turned upside down and very often redefined. Without taking cognisance of these developments and changes, and rethinking our practices along these lines we will remain behind and increasingly so. Eventually it may become difficult, if not impossible, to catch up.

We must be careful not to allow our workplace to out-develop us; we have to remain in step. We simply have to keep track and pace in an intelligent way with the developments, theoretical and practical, in and around our workplace and related to our workplace. This implies thorough rethinking of knowledge and information along new and completely different lines. Knowledge work cannot be pursued without such new explorations and reflections. For this purpose it will be useful to use an example. One of the most brilliant examples regarding a conception of knowledge and a comprehensive understanding of the place of knowledge and its dissemination in and usefulness for society is most certainly the work done over many years by the French thinker, Michel Serres. His articulation of the understanding and promotion of knowledge in society in terms of the mythical figure of Hermes, together with his development of the notion of 'the atlas of knowledges' (Serres 1994), offer a unique and significant point of departure for our discussions. This article is a tribute to Serres' delightful philosophy of information and knowledge, with a strong focus on the intellectual challenges posed by him in the following statement regarding knowledge and information: "Let us nevertheless try to see on a grand scale, to enjoy a multiple, and by times connective, intellection" (Serres 1980:24). In a significant series of essays Mapping Michel Serres, edited by Niran Abbas (2005), the close, intimate, but also flexible, knitting together of the three terms multiple, connective and intellection, is clearly demonstrated and shows how fundamentally important they are to the core of his philosophy and especially his philosophy of information and knowledge.

\section{The intellectual pursuit of the multiple fullness of knowledge}

The reflection on the acritical philosophy of information and knowledge of Michel Serres articulated in terms of Hermes, the messenger of light, makes quite exciting and lively reading. It confronts us with a new and fresh conception of knowledge.

The most appropriate discussion in this regard is Serres' introduction to his book Hermès 1: La Communication (1968), which is the first volume in a series of five with the general title Hermès $I-V$. This introductory chapter gives an excellent overview of the most important arguments used by Serres to demonstrate the difference between a critical/dialectical and an acritical/network approach. The Hermes series, together with other later publications, constitutes Michel Serres' philosophy of information and knowledge. According to him this 
philosophy accommodates communication as well as a philosophy of science with very clear ethical undertones.

Bruno Latour (1987), in a brief essay on Serres, introduces the most suitable and appropriate term 'acritical' as the main characterisation of his philosophical work. In a published interview with him a whole section of the book was devoted to 'The end of criticism' (Serres 1995d:125-166). Serres' acritical philosophy lives under quite different assumptions than those of the critique movement. There is no centre and no substitution of one metalanguage that could overmaster all the others. The result of his commentary is a crossover, in the genetic sense, whereby characters of one language are crossed with attributes of another origin. Latour sketches the Implications: 1. Who does not want to have or take over a centre, does not need to train a retinue of followers? And 2.Be as inventive as the text, be as inventive as I am when inventing the text anew.

What is our task in the information era against this background when there is no belief in metalanguage, when history has not been divided up by revolutions, when mastery has not overmastered the world? What sort of enlightenment does one get when there is no critique? What emancipation is in store? What ethical implications are to be entertained? These questions formulated by Latour are indeed explored by Serres' philosophy.

What should be attended to is the relationship between an acritical philosophy per se and an acritical philosophy of information and knowledge. The two belong together and will be dealt with in that sense. Some crucial moments in his thinking will he highlighted. At the same time it would be necessary to understand his differentiated understanding of information and knowledge, both of them are quite complex issues in their own way, and which differs substantially from the current usage of these terms in the informationalistic context. Serres as philosopher of information and as philosopher of knowledge may sound strange since we may feel that he cannot possibly be both. This remains strange until it is realised that Serres is not using either knowledge or information in the current generally accepted sense in which these terms are very often used interchangeably and are even deeply violated by this. He digs down into the depths of both knowledge and information and understands them as different sides of the same coin, but certainly not merely as variants either.

Serres is explicit: "The greatest difficulty lies in my wish to be encyclopedic, followed by my desire for synthesis, in the hope of going everywhere, of not missing anything in order to gradually build a world. ... The era of suspicion and of hypercriticism only spoke of fragments, of local pieces, of criticizing and destroying. So, it was necessary to leap aside to avoid being dragged along. Assembling, accumulating facts, the voyage into the totality of knowledge and experiences - these have their difficulties, ... but they also presuppose a distancing on the part of the person doing it" (Serres 1995d: 126-127). Regarding information theory he stated: "My true training consisted in witnessing - almost participating in - a profound change in this fundamental science [mathematical research]. From there I became highly sensitised to analogous transformations in other domains - whence my swift acknowledgement of Brillioun's work, of information theory in physics, and much later of questions of turbulence, percolation, disorder and chaos. ... Physics was changing, was revealing a whole new outside world. After fractal curves and strange attracters, you no longer feel the same wind, no longer see the same waves, or the same shores as before" (Op. cit.: 1112).

Serres' philosophical reflections on the nature and impact of knowledge and of information make him a philosopher of both information and knowledge. For him they are not 
interchangeable; neither are they simply complementary; they are interweaved and interconnected in multiple ways and are most certainly not merely to be seen as variants. This understanding of information and knowledge asks for a Hermes to digest knowledge as a complex and dynamic entity into clear information messages able to change and transform the world when properly distributed and translated.

Against the background sketched above I want to simultaneously do different things with this article: introduce the philosophy of information and knowledge of Michel Serres and why it deserves more reading than it receives; show that knowledge is a much more complex issue than our research endeavours and institutions, and more recently 'knowledge management companies' try to make out; indicate that all forms of knowledge are to be taken seriously; emphasize that humans, us, are challenged to be inventively involved with the issue of knowledge; show that knowledge (and not any deformations of it, and also not its disfigurement by powers like rhetoric, or political systems and ideologies, or colonizations, or decolonizations, nor the market), and knowledge only, is the issue that can take us (the human race and respective societies) forward in any sensible way; and emphasize these matters in such a way that it will form food for thought and further discussions.

The implication of the title as well as the contents of the article, although not fully spelled out, demonstrate another form of globalization, forced on us by pure theory, as well as information technology (and not information technology). The actor/network theory, inspired by Michel Serres, the grounds of which werealready well articulated in 1968 ( $L a$ communication), as well as his core oeuvre rotating around the Hermes figure, and his neverending involvement with and indulgement in information and knowledge, all demonstrate the unlimited scope of the transgression of boundaries and the mobility of the nomad. Another perspective, much more constructive and much less threatening than the economic/market version of globalization emerges in this view. This input is, however, not without intersection with the other one. As a matter of fact, much of what they have in common are there links to electronic media. We should never forget that the theoretical perspectives developed with global implications were not in its initial stages inspired or supported by electronic media. As a latecomer to the scene these media indeed reinforce, activate and intensify these theoretical views immensely. One of the more recent publications of Serres, Angels, a modern myth (1995a) is a particularly relevant publication in this regard since this is exactly what he articulates in this publication.

Reading Michel Serres is like visiting paradise - the garden of Eden - I imagine: Scintillating, jubilating, sparkling, surprising, adventurous, unknown, enriching, playful, harmonious, refreshing and joyful experiences. Reading on or about him leaves one easily with this kind of experience. There is a freshness and a sparkle which reminds of the cleanest air one can only find high up in the Alps. After I said to myself that this is how I experience the writings of Michel Serres, I read what Pierssens (1979: 102) writes: "To read Serres means to rest on a window pane in order to discover an immense horizon, the inexhaustible of the present; it means to receive, with one blow, the wind of a thousand hurricanes which leaves everything uncertain: the certainties of fiction, the reveries of science, the neatly argued pathos of philosophy." And again "Serres is not an aesthete, but an artist of philosophy. Integrity of this beautiful art, gravity of this dance, aesthetics and logic make a complete circle" (Debray 1979: 18). Moreover, Serres himself is not hesitant to express his views along similar lines: "Knowledge is born happy. It can be shared, happy, without being able to be divided. It multiplies, of itself, fruits of rejoicing. ... Knowledge is born happy for the 
attentive solitary or the team at work. ... Now, in the institutions that manage, exploit and transmit it, for the individuals crushed by it, it feeds, in fact, the death instinct. ... How can knowledge be returned to its proper nature? It is urgent to answer that question" (Serres 1974:74-75), and again, to further emphasize his celebration of knowledge he writes: "Drugged by knowledge? I love that knowledge gives us life, cultivates us; I love making my home in it, that it helps me to eat and drink, to stroll, to love, to die, sometimes to be reborn; I love sleeping between its sheets and I love the fact that it is not something outside me" (Serres 2008:103). But then he moves in another direction: "Traditional philosophy usually has either a central god who is a producer, a radiating source of life like a sun, or a story of the origin of time. My philosophy is more like a heaven filled with angels, obscuring God somewhat. They are restless, unsystematic (which you find suspect), troublemakers, boisterous, always transmitting, not easily classifiable, since they fluctuate. Making noise, carrying messages, playing music, tracing paths, changing paths, carrying...." (Serres 1995d:118). Must I really repudiate such a mentor. Who cannot and do not want to associate with this Serres may be wise to take leave. In this capacity he revolutionizes our conception of knowledge by linking it to all possible other discourses. In this regard he is not alone, but certainly gives his own stamp and flavour to the process of revolutionizing knowledge. The rest of the article will elaborate on this "revolution".

Another way of making the same point is a reminder of Merleau-Ponty (1969:34) who once wrote: "Meaning is like spots of light surrounded by rugged clouds of night, glowing islands." Michel Serres' oeuvre is remarkable since it tries to link these spots of light - these islands as well as the rugged clouds of night in a harmonious way: The web of meaning which can neither nihilistically deny light, but at the same time, in terms of which it cannot apocalyptically be pretended that all we see is light and that there is no darkness, nevertheless has to accommodate darkness. The recent debates about chaos, order and complexity are relevant here. His 'Hermes philosophy' is about these debates. "One of the most beautiful things that our era is teaching us is to approach with light and simplicity the very complex things previously believed to be the result of chance, of noise, of chaos, in their ancient sense of the word. Hermes, the messenger first brings light to texts and signs that are hermetic, that is, obscure. A message comes through while battling against the background noise. Likewise, Hermes, traverses the noise, toward meaning" (Serres 1995d:65-66).

Some views along these lines which make the self-sufficiency of our generally accepted views on knowledge ludicrous and highly questionable and therefore risky are the following:

Jean-Francois Lyotard (1988), the philosopher, in Peregrinations, writes about the importance of doing away with 'the delusion of consistency' (the attitude reflected in the so-called 'old knowledge') without shying away from the complexity of things. He writes: "It is time to complicate a bit our approach by opening up gaps inside what is certainly a too thick cloud of thought in order to do away with the delusion of consistency and to make ourselves receptive again to more intricate events" (Lyotard 1988:28).

Hundertwasser, the artist, is even more explicit: "In 1953 I realized that the straight line leads to the downfall of mankind. But the straight line has become an absolute tyranny. The straight line is something cowardly drawn with a rule, without thought or feeling; it is the line which does not exist in nature. And that line is the rotten foundation of our doomed civilization. Even if there are places where it is recognized that this line is rapidly leading to perdition, its course continues to be plotted... . Any design undertaken with the straight line will be stillborn. Today we are witnessing the triumph of rationalist know-how and yet, at the 
same time, we find ourselves confronted with emptiness. An aesthetic void, desert of uniformity, criminal sterility, loss of creative power. Even creativity is prefabricated. We have become impotent. We are no longer able to create. That is our real illiteracy" (Hundertwasser, as quoted in Peitgen \& Richter 1986:v) .

Mandelbrot (1982:12), the geometrician, very clinically puts the same problem in perspective when he writes: "Why is geometry often described as cold and dry? One reason lies in its inability to describe the shape of a cloud, a mountain, a coastline, or a tree. Clouds are not spheres, mountains are not cones, coastlines are not circles, and bark is not smooth, nor does lightning travel in a straight line... . Nature exhibits not simply a higher degree but an altogether different level of complexity. The number of distinct scales of length of patterns for all purposes infinite. The existence of these patterns challenges us to study those forms that Euclid leaves aside as being formless, to investigate the morphology of the amorphous. Mathematicians have disdained this challenge, however, and have increasingly chosen to flee from nature by devising theories unrelated to anything we can see or feel."

A fairly recent publication (and the related exhibition in Paris, France) entitled, Measurement and the unmeasurable, edited by Bernardis and Hagene (1995), demonstrates in various ways to what extent the measurable is not reliable and that our decisions, even scientific ones, are very often affected and directed by what cannot be measured. We should never be tempted to confuse knowledge with the measurement of knowledge. These two entities, although they are somewhat linked, are also incompatible.

These views cut deep into the heart of our knowledge culture, and consequently our information culture and calls for drastic revision, rearticulation, and rethinking.

This is exactly what Michel Serres has been doing for the past 30 years years and is still working on currently. His works are, each of them in its own way, an effort, and a very successful effort, to articulate precisely these issues related to a new knowledge culture. See for example the book by Assad (1999) in which she offers lively interpretations of and comments on some of his books. Compare also a few very recent books by him on this same theme (Serres 2009a; 2009b).

Three general and very dominant features of his project of thinking that have an impact on all his other themes should be mentioned and eventually also explored: he is an acritical philosopher; he is a philosopher of networks and invention. These two outstanding characteristics of his thinking determine the mode of his oeuvre. Each work stands in the light of an acritical inventiveness. These are reinforced and inspired by connectivity. Networks are enabling factors for inventions. This makes of his thinking with the focus on multiple, connective intellection something drastically different from the enlightenment philsophy and the entire tradition of the critique philosophy.

\section{The intellectual establishment of multidisciplinary connectedness between knowledges}

In view of the above discussions, instead of subjecting his work and views on information and knowledge and his views on reality to an epistemological and an ontological critique, in line with the critique tradition, his views and conceptions of knowledge and reality, which are complementary, will be briefly exposed in its richness and fullness in order to demonstrate the multiple nature of the real and of the act of knowing. It is important, however, to take 
cognisance of his attitude towards epistemology and technical philosophical jargon in general in order to understand the absence of this way of thinking which is similarly responsible for not classifying his philosophy or relating him to other philosophers.

Michel Serres has taken leave of technical philosophical jargon because of his conviction that they are sterile. For this reason he prefers to abstain from using terms such as epistemology and ontology. This certainly does not mean that he has taken leave of the real or of knowledge. On the contrary, he is adamant that these terms contaminate one's understanding of knowledge and of the real. He made it clear that he "was irrevocably condemned to abandon the classical or technical style of philosophy because ... it didn't have the terms or operators capable of describing the method of moving from mathematics to style" (Serres 1995d:71). He goes even further: "Technical vocabulary seems even immoral: it prevents the majority from participating in the conversation, it eliminates rather than welcomes..." (Op cit. 25). And then he continues: "Epistemology implies that rationality exists only in the sciences, nowhere else" (Op cit.:128). Only scientific knowledge defined in certain terms qualifies as true knowledge. For Serres this cannot be. For this reason he "took leave of epistemology (Ibid.). To this he adds: "The best contemporary myth is the idea of a science purged of all myths" (Ibid.).

Serres' allergy to the technical vocabulary of philosophy, the fact that he has taken leave of epistemology, and his reliance on characters such as Hermes and Angels in no way suggest that his position is a flight into the irrational. He is very explicit about this. He has not taken up an irrationalist position. "Not at all", he says. "I am a rationalist in most of my actions and thoughts - like everyone. But I am not a rationalist if reason is defined as an ingredient only found in science. This restrictive definition is not reasonable. ... Yes, I am a rationalist ... But this rationalism also applies to domains beyond science" (Op cit. 1995:129). This differentiation must be dealt with carefully. As long as we continue to define rationality in terms of scientific rationality we limit reason in an unreasonable way since we deny reason any other valid activity. But what is more: reason in this way understood cannot per definition take us beyond the rhetoric of disciplinary work. It is made for disciplines and as such "reason never discovers, beneath its feet, anything but its own rule" (Serres 1997: xiii). What happens 'between' the disciplines cannot be accommodated by this kind of rationality and therefore reason needs to be redefined so that Hermes and the Angels can be accommodated. This redefinition may sound like irrationality, but is far removed from the irrational. As Serres (1997:71) explicitly stated: "The instructed-third [the mature knowledge worker, the spiritual person] owes his upbringing, his instruction, and his education - in all, his engendering - to reason, a brilliant sun that commands scientific knowledge as much as the second reason, the same one certainly, but burning in the second focus, which comes not only from what we think, but from what we suffer. This latter reason cannot be learned without cultures, myths, arts, religions, tales, and contracts. The social sciences [all sciences for that matter] are dying from having forgotten the two fundamental modes of reason, that of the sciences and that of law, the one that comes to us from thought and the one, also universal, that the problem of evil - injustice, pain, hunger, poverty, suffering, and death inspires in us and that has produced artists, judges, comforters, and gods [producers of meaning]. There is only one authentic reason. It illuminates and mobilizes through two forms: without the first, bright, the second would be irrational, but without the second, hot, the first would be unreasonable."

It should be clear from this that the Angels and Hermes as used by Serres would comply with the second mode of reason, an equally valid form of reason as the first. Hermes represents our 
ideas and our behaviour, our theoretical abstractions but also our works, our technology, our experiments, our laboratories where "everything functions through networks of complex relations between messages and people” (Serres 1995d:114).

Closely linked to this he continues: "What could be more luminous than a space traversed with messages. Look at the sky ... it is traversed by planes, satellites, electromagnetic waves from television, radio, fax, electronic mail. ... Why shouldn't I call it angel space since this means the messengers, the systems of mailmen, of transmissions in the acts of passing or the space through which they pass? ... The angels are the messages ... Pure multiplicity" (Op cit.:118-119). Even myth contains, for him, a valid dimension of rationality but this would require an additional article.

I prefer to honour Serres' views and am happy to give an overview of his views of knowledge and of the real without engaging in technical philosophical jargon and style. It would be unfair to him and his work to force his remarkable theoretical achievements in his oeuvre into ontological and epistemological analyses and classifying strategies. We need to liberate ourselves from this style and jargon if we hope to be able to engage knowledge in nondisciplinary and trans-disciplinary terms, Michel Serres' speciality. Epistemology and ontology, as is the case with classification and comparison, are disciplinary reflections in the critique tradition and not appropriate to be applied to Serres' philosophy of information and knowledge.

Michel Serres' book Atlas (1994) is more or less the converging point of his views in the five books in his Hermes series. The views expressed in these publications introduce to us the idea of a road map for knowledges (cf the History of science). This is the idea of giving or working on a comprehensive, all-inclusive map of the world of knowledge, which is at stake here, and what can be referred to as 'worldmapping' (Serres 1994:109-112) in terms of the new conception of knowledge in its fullness.

The history of the thinking of Michel Serres is a history of wrestling with the issue of knowledge. All his books centre around this theme and each one of them elaborates and highlights a particular perspective on this issue. Themes addressed by his many books on themes like communication, translation, interference, distribution, passage, statue, five senses, genesis, detachment, Hermaphrodite, Rome, Atlas, and more are all weaved around this formidable theme, so totally indispensable for the human race and at issue since the beginning of human history. Compare the history of religions and cultures and the role knowledge constantly played in all these cultural traditions. Knowledge and its importance for human life and existence is no new invention, least of all an invention of the sciences or of the marketplace. It certainly has not suddenly become an important theme because it is surprisingly included in the rhetoric, vocabulary and marketing strategies of big companies, or finds a strategic place in organizational politics, or in business and management contexts where it has never been a prominent issue before.

Serres' deep, honest and authentic urge at the end of his book, Detachment (1989a), namely "let the new knowledge come" (Serres 1989a: 177) eventually culminates in the statement in one of his more recent books, Atlas, in the following terms: "We should no longer run after a knowledge universe, but pursue the multiplicity of possible knowledge worlds" (Serres 1994:11). In this book he unravels the zig-zag tours and detours leading to an illuminating enlightening focus point where all routes related to knowledge and to the real converge and come together in a single knot - harmonious, significant, and meaningful. In order to confirm the nature of the knot his conception of the real as articulated in his book Genesis 
(1995b) should be added : The object of this book is the "multiple" (Serres 1995b: 4), according to him "a new object for philosophy” (Serres 1995b:2).

Traditionally we are fascinated by unity; unity seems rational to us both regarding knowledge and the real. That is exactly the rational aim of all epistemologies and ontologies with the implied claim "of always being right". Serres wants to subvert this focus with his "new object of philosophy" (Serres 1995b: 2), namely the multiple. Despite the fact that "reason still insists on ignoring it" (Serres 1995b: 6), Serres emphasises that it is absolutely "natural'. He writes: "The multiple as such, unhewn and little unified, is not an epistemological monster, but on the contrary the ordinary lot of situations, including that of the ordinary scholar, regular knowledge, everyday work, in short, our common object" (Serres 1995b: 5). This knot constantly requires to be untied. In his reflections on knowledge and the real, information is never far behind and never left out of the picture. As a matter of fact it finds a very special place as it has already been indicated above. Serres can indeed be called one of the most productive, imaginative and inventive philosophers of information.

We need an atlas to guide us through landscapes, countries, and so forth. Without it we will easily get lost. Equally important is an atlas for the landscape of knowledge, and its place in culture and society. Hence, his exercise in mapping the world of knowledge as comprehensively as possible. Knowledge as map or atlas is needed in a much more comprehensive sense than merely for purposes of physical moving around. Knowledge is the issue that enables us to find our ways and directions through life. It is indispensable for us as living beings.

Atlas represents a more comprehensive and open-ended notion than encyclopaedia, which is closed and finite. This rethinking of knowledge in new terms is made necessary by the development of a new conception of knowledge, which emerged during the past number of decades, with vast implications for the creation, dissemination, transmission, and utilization of knowledge for the well being of society. These new developments also pose serious new challenges for the activity of thinking, the fantasia of thinking, and the pursuit of science in the sense of nomad science. Gilles Deleuze and Felix Guattari, together with the mathematician René Thom, are key thinkers on these matters who incidentally had close connections, especially in an intellectual sense, with Serres. (See De Beer 1998).

Serres (1994:276) prefers to speak of 'a multiplicity of possible knowledge worlds', rather than the classical 'knowledge universe', and that for self-evident reasons. These reasons became prominent in solid theoretical terms but also supported by developments in the area of electronic media which certainly facilitate these new developments. Hereby human thinking is confronted with dramatic challenges. In a similar way as our talking of networks of roads (represented by the idea of atlas) we can speak of networks in a more abstract sense, referring to the links between knowledges, institutions, insights and many more related issues.

This calls for a clear awareness of and sensitivity towards the idea of a knowledge and information space. This does of course not mean that parts like individuality, uniqueness and other entities are destined to be neglected or even to disappear. Space is important precisely because it creates the 'space' within which the connecting of individuals, of parts and of uniqueness can take effect in a multiplicity of intelligent ways. By establishing and changing connections room for inventions is created. Inventions without the connections are impossible hence the emphasis on 'multiple connective intellection'. Space in Serres' sense does not make individuals superfluous or make them disappear but grant them a special and unique place instead. 
Serres developed his theory of networks of communication at an early stage (Hermès 1:La communication 1968). This in itself offers a model of communication more adequate and significant than the well-known linear model of Shannon and Weaver. He uses the term 'tabularity' to describe his position. This theory can be made fruitful for other linkages as well, very useful from the point of view of knowledge usage. We can easily detect from what has already been stated that the notion of space, real and/or virtual is selfevidently suggested. Atlas, maps, networks are all spatial terms. Knowledge space and information space will become crucial issues in this regard, and very importantly so, as a space to be inhabited!

Real space implies the following: Does a road exist of which one could indicate the exact departure point and point of destination? Virtual space, on the contrary, entails the following: if Hermes carries his messages only to a unique sender ..., while Leibniz, like the Angels, describes the passages from whatever place towards the universe, or from this global point to such sojourn by virtual intermediaries, it becomes perfectly clear from where the idea to design these sheaves in worldmaps, in an Atlas originated. His whole oeuvre rotates around this theme: communication between the sciences, between knowledges, between the sciences and societies, and movement in all directions. For this reason the notion of space is important as well as mapping knowledges in this space. A brief look at his works will somehow illustrate this. At the same time this way of articulating knowledges emphasizes self-evidently the idea of a new knowledge that is not a given but should be pursued.

Serres' notion of communication involves transfers from one science to another, or from the purest science to philosophy and even poetry. Communication traverses these spaces that would be much less clear and transparent than one would have believed. The titles of many of his books, like communication, interference, distribution, translation, North-West passages, lighthouses and fog horns suggest movement from place to place, movements within space. Not things and operations but relations and rapports are what he is concerned about. A reading of his books may seem difficult since it always involves changes and moves. This changing and these transformations and these wanderings either follow or invent the path of a relation, relations between the sciences, between knowledges, between humans and knowledges, and between humans, knowledges and the real. The emphasis on space brings forward the space between knowledges, the space between disciplines, the connections and possibilities of connections and connectivity between knowledges, and between disciplines within this space, in the 'between' of knowledges and disciplines, and the relatednes or connectedness between knowledges, disciplines and the real. These relations are continuously to be established. He writes: "The space between - that of conjunctions, the interdisciplinary ground - is still very much unexplored. One must travel quickly if the thing to be thought about is complex" (Serres 1995d:70).

When one reviews his works it will be possible to retrace easily how he passed from mathematics to physics, from physics to the life sciences and to the human sciences, without ever leaving behind its historical component. But these movements do not make up a seamless list which occuppies a flat space. They suggest a hilly landscape, ondular pathways chaotic and fractal, much closer to reality. In Crahay (1988:13-14) we find a beautiful description of the real in line with this description:

[B]eing is no longer substance but made up of appearances, of events and encounters, of relations, of qualities of meanings; the infinite remains undetermined; the ontological reality remains undifferentiated chaos, mixed multiplicities; and philosophy is the tacit place of welcome where all roads come together, get mixed and melt into one another.... 
Besides utilizing concepts by which he wants to facilitate movement and communication in a successful way he also uses characters which find expression in some of the titles of his books as well. Some of these characters are: Hermes, Parasite, Hermaphrodite, Harlequin, troubadour of knowledge. In these books where he meditates on successful communication, the difficulties, obstacles, and conditions pertaining to transformations, movements, communications and translations are laid down in detail and make for fascinating and exhilirating reading.

A brief illustration of how Michel Serres in his books tries to establish relations between disciplines, but also between ideas and relations as conditions of our knowledge creations and the world in which we live and which we create in some way may help us to better understand the idea of the atlas of knowledges, the idea of the urgency of a new conception of knowledge, and why a comprehensive worldmapping of knowledges is required. How sociology is situated in astronomy (the two most distant sciences in terms of positivism's classification) is discussed in his Origins of geometry (1993). How politics is situated in physics is the great question in The natural contract (1995c). How technology and physics are both situated in an anthropology of death is the main concern of Statues (1987a). The possibility of fitting together information theory, parasitology and table manners is discussed in The Parasite (2007). In his book on Zola (Lighthouses and fog horns) (1975) he situates thermodynamics with genetics and both of them with the history of religion. The question he tries to answer in Hermaphrodite (1987b) is how it is possible to link the symmetry/assymetry of left and right, of orientation and of sense in the physical and in the human sense of the word? These passages between the disciplines or sciences are explored in a very specific sense in The North-West passage (1980) and strongly recommended for teaching in The troubadour of knowledge (1997). The equal relevance of all knowledges, especially the validity of the sciences of the spirit are strongly emphasized by Serres quite recently in his little book on "writers, scientists and philosophers" (2009a). Nothing can be more relevant for knowledge and information workers - we simply have to undertake these journeys and on a continuous basis. This is a demanding challenge but hardly anything can be more rewarding at the same time.

\section{Some specific intellectual demonstrations of a theoretical and practical nature of of relevance for the spontaneous embracement of the new knowledge}

Some core themes emerging from the reading of Serres' oeuvre and that relate to the embracement of a new conception of knowledge, deserve attention and may prove to be enlightening in more than one respect as well. In order to articulate this pursuit of the new knowledge and to engage in the processes of designing the comprehensive atlas that has been referred to, certain core areas are identified as focal points for illustrating that all of them are extremely relevant, not only for establishing links between knowledges, but also for the exploratory pursuits Information Science ought to get engaged in, as well as the knowledge practices that flow from this.

\section{i Atlas of knowledges}

The issue of knowledge networks (very contemporary) immediately springs to mind. The actor/network theory in Sociology emerges from these insights on networks (multiple connective intellection) and the link between knowledge and action. Knowledge, information, science, literature, philosophy, labyrinth, networks, crossroads - are all linked! 
Let the new knowledge come (Detachment 1989a:177). This formidable theme is discussed from the first volume in the Hermes series to the very latest publications. It is all the time a matter of knowledge/information for Michel Serres - only one of a few real philosophers of information. In the middle of his publications appears this exclamation: let the new knowledge come! (Ibid.).The notion of atlas of knowledges does not create room for criticism which limits freedom of movement, but for an acritical attitude which encourages movement of thought. 'So - stand up, run, jump, move, dance! Like the body, the mind needs movement, especially subtle and complex movement' (Serres 1995d:107).

\title{
ii Language and structure
}

Michel Serres' book, The five senses (2008), is a protest against 'the empire of signs' and the all-inclusiveness of language in certain circles, especially in Paris under the influence of structuralism. He writes about his own book in the following words:

\begin{abstract}
Il around us language replaces experience. The sign, so soft, substitutes itself for the thing which is hard. I cannot think of this substitution as an equivalence. It is more of an abuse and a violence. The sound of a coin is not worth a coin; the smell of cooking does not fill the hungry stomach; publicity is not the equivalent of quality; the tongue that talks annuls the tongue that tastes or the one that receives and gives a kiss. My book Les cinq sens (The five senses) cries out at the empire of signs (Serres 1995d: 132).
\end{abstract}

\section{iii Pragmatogony}

This refers to subjects who are created by objects, and not in the first place subjects manipulating and molding objects. The object is the horizon of knowledge, and not the initial reference of its exercise. In this sense the object becomes a project (Serres 1972:63). Felman (1979) wrote a remarkable article on this. These views open the road to an ambitious anthropology of science which emphasizes the impact of science on humans.

Our tools ... are simultaneously objects of this world and objects of society. Every technology transforms our rapport with things ... and, at the same time, our relations among ourselves (Serres 1995d:141). (See De Beer (2010) for a discussion of this theme).

\section{iv Messages}

Angels and cyberspace are the issue here. From Hermès 1: La Communication (1968) to his publication on the body, Variations sur le corps (1999), as well as his latest publications, he is dealing with this issue. Hardly any theme can be closer to the point regarding the contemporary knowledge and intellectual theme than the one of message and the circulation of messages. 'What could be more luminous', he asks, 'than a space traversed with messages? Look at the sky, even right here above us. It's traversed by planes, satellites, electromagnetic waves from television, radio, fax, electronic mail. The world we are immersed in is a spacetime of communication. Why shouldn't I call it 'angel space' (See The legends of the angels (1995a),since this means the messengers, the systems of mailmen, of transmissions in the act of passing or the space through which they pass? ... Indeed, we live in the century of angels' (Serres 1995d: 118-119). 


\section{$v$ Bodies and the five senses}

Dare one emphasize this in 'the age of the spiritual machines'? (Kurzweil 1999). Currently there are complex interplays between embodied forms of subjectivity and arguments for disembodiment throughout the cybernetic tradition. The erasure of embodiment is a feature of both the liberal human subject and the cybernetic posthuman. The Parasite anticipates the notion of the posthuman. Identified with the rational mind the liberal subject possessed a body but was not usually represented as being a body. How exactly is the body to be understood: as an object of control and mastery rather than as an intrinsic part of the self? Fantasies of disembodied immortality are alive and fresh right now! Variations sur le corps (1999) is coming in from a slightly different angle, describes the admirable metamorphoses that human bodies can accomplish like athletes, dancers, clowns, artists, etc. Animals lack such variety of gestures, postures and movements. Supple to the point of fluidity the human body can imitate with ease things and living beings. Moreover it creates signs! The five senses are not the sole source of knowledge; knowledge emerges to a great extent from the imitations that render possible the extraordinary plasticity of the body in its entirety. In it, with it and by it knowledge commences. This view leaves the spiritual machines of Kurzweil (1999) behind.

\section{vi Method}

This is a strategy for the lazy. 'It is reasonable to be reasonably wary of the rational'. Serres is seeking a knowledge that is finally adult, a balanced wisdom, a certain forgetfulness of death... the adult person is educated in a third way... . It is the acritical individual the one who knows what it really means to read.

"What is more lively than the improbable unexpectedness of findings? Who is more profoundly boring than the repetitive reasoner who copies or seems to construct by constantly repositioning the same cube? Ruminating on the past - what a system! Repeating a method - what laziness! Method seeks but does not find (Serres 1997:100).

\section{vii Reading}

Reading as poaching, or even as castration versus reading as invention - this is our alternative. All knowledge is to be taken seriously. Collective intelligence; sharing; reading with others; acritical reading, all these reflect the views of Serres on reading (see Latour 1987). Latour's views can briefly be summarised in the following way:

\section{Tell me how you comment on a scripture or an inscription, and I will tell you what kind of epistemology you hold on to (Op cit.: 86).}

And then he continues: "Understanding Serres' conception of commentary is thus also a way of understanding his conception of the sciences" (Ibid.).

\section{The critique tradition of literary criticism and comment}

The critic has a vocabulary; but so has the text under scrutiny. (1) There is a question or direction: which one does the interpretation? The critic of course in terms of his/her metalanguage that makes sense of the infra-language of the text. (2) There is a question of size: the critic's vocabulary is enormously shorter than the text's repertoire. This is why the metalanguage is said to explain something. With two words in the critic's repertoire, for instance Oedipus complex, many novels or plays can be explained. (3) The question of precedence or of mastery: who dominates the other? The commentator: critics are much 
stronger than the texts they dominate and explain, establish and analyze. The mastery is so complete that texts, novels, plays, myths, etc are buried beneath stronger, more powerful commentaries.

Serres as example of a marvellous reader... an acritical reader His principle:

The text under scrutiny is always more rigorous, more lively, more modern, than the commentator and always provides a richer repertoire. Who turns around them? The commentator. Who overmasters bim? The humble and outdated texts (Latour 1987:89).

He would rather appeal to the pure beauty of the text beyond the boring scholarship of the critique.

In this case (1) There is no metalanguage, (2) It is impossible to distinguish the provider of an explanation, the commentary, or the commented text? (3) There is no precedence and no mastery either.

What he does on the relation of the commentary to the text, and of the text to things, he also does it on the relationship of texts to things and on the relations of the sciences to the world.

This reading is a breaking out of the static order (the order of statues) and the embracement of chaotic fullness - the birth of a new knowledge. A move from the clarity of light to the hopeful vagueness of glimmers (Serres 1987a).

\section{viii Troubadour of knowledge}

The educated third, as presented to us in this character, to which a whole book is devoted (Serres 1997). We must imagine a way to teach, with the same gesture, both the poem and the theorem, both the immortal world of scientific laws and the new age of the arts. Those taught the third approach to knowledge will have chucked the death wish. This publication is not only offering a delightful model for the knowledge worker to pursue. At the same time it is specifically relevant from the point of view of invention. Or in the words of Assad (1999: 128): this book

is a book on education in the largest possible sense of the term: the all-encompassing formation of human thought as invention; and inventive creativity as the only actvity worthy of cognitive thought.

The essential characteristics of the troubadour can be stated in the following way emphasizing the special requirements for the knowledge worker, the knowledge organiser, the troubadour of knowledge given the mood of the contemporary era. 1. They should develop a sensitivity towards knowledges, all knowledges - the instructed third; 2 . They should be willing to navigate, travel, search in a special mode that complies with the new knowledge dispensation; 3. There must be a keenness to become an eternal learner - who never stops, always looking for new knowledge and insight; 4 . An equally eager enthusiasm to read and to read well, but to read differently, will be an essential requirement; 5 . The overwhelming challenge of the contemporary situation is to excel in thinking, to refuse to merely repeat what is given, or to fall into the trap of repetitive thinking; 6 . A commitment to engage in an "eternal conversation" with a willingness to cross boundaries is non-negotiable; 7. All these qualities will emerge from a well developed imaginative noetic capacity as its condition - human beings are spiritual beings and this quality should be manifested in their 
enthusiasms; 8. Inevitably this would lead to inventiveness for real problem-solving in a new and not a fake way.

\section{ix Invention}

This is a core issue for Serres which he considers as the only true intellectual act, the only intelligent action. Lack of invention proves the absence of works and of thought. Life as invention, that is, thought is central for him. "I think therefore I invent, I invent therefore I think" (Serres 1997:193). Fortunately this is not how scientific work necessarily proceeds.

Sadly, the time has come when the sciences are letting themselves get trapped in the customary subservience of groups who are looking only to perpetuate themselves as a group. Thought can only live free from these constraints. The misfortune of our times is that these constraints are precisely those of thought as such: exactitude, rigorousness, precision... Hence our narrow margin, our small degree of freedom: thinking with scientific thinking, but especially thinking outside of it, knowing how to free oneself from these stifling regulations, but also knowing how to regulate this freedom. Inventive reason has before it but the eye of a needle to be able to pass through, freedom tempered by rigor (Serres 1995b: 105).

As a matter of fact, Assad (1999) highlights invention as the core, the real focus and objective of Serresian philosophy, "the singular notion that may be said to traverse all of Serres' writings..." (Assad 1999:7). Not repetition, not memories, but invention - new beginnings, new findings ... that's why reading him is so exciting and reading according to him is equally exciting. Closed, repetitive systems smother invention.

\section{$\mathrm{x}$ Knowledge as remedy}

For Michel Serres knowledge, in the proper sense, has a healing function. He devotes a substantial paragraph to this, entitled 'Healing at Epidaurus' (2008:85-106). He writes:

I love that knowledge gives us life, cultivates us; I love making my home in it, that it helps me to eat and drink, to stroll, to love, to die, sometimes to be reborn; I love sleeping between its sheets and I love the fact that it is not something outside me (Op. cit. 103).

And again; "Wise knowledge heals and molds the body, it embellishes" (Op. cit.:105). In many places in his writings he mourns

the sad condition of currently accepted knowledge in its closedness, limitations, imprisonment and even death, and finds the solution, 'the only solution', to this in the liberation of knowledge, which means the suppression of all forms of secrecy, of every coding, obedience and prescriptiveness and a definitve move towards invention" (Serres 1974:88).

Auzias (1992:1996) summarises Serres' views about the anxieties of epistemology, the handing over of science by positivism in the hands of the sick who only enjoy the maximum of power, of knowledge as an exercise in the ideology of command and obedience, specialisation with its creation of closed rooms in the way of a question: Is this without remedy? The answer is: No, the remedy is the joy of knowing!" The real nootherapy, however, is to be found

in love, not in war. Love and not war requires plenty of talent. The power that one finds in the people, a positive relationship to the life that is missing from intellectuals, 
bourgoisie, the military and politicians. What is needed is a calm power, tranquil, quiet, stable and serene. Tenderness. What is needed is a knowledge and a knowing capacity, this vital fortune that gives everything in a smile, this gentleness, this high geniality of greatness in bodily relations. The only art there is, is namely that of mobilising all forms of meaning. What is needed is philosophy in its fullness and wholeness, the true, the one with its feet on the earth and who deciphers the wisdom of love, an actual perception of the omnitude of the cosmos, the total fullness of human knowledge and knowing. And, you would like society to stop adoring hatred and death, in order to adopt roads of equal difficulty..." (Serres 1974:94-95).

This may provide the remedy so urgently needed.

\section{Bibliography}

Abbas, N. (Ed.) 2005. Mapping Michel Serres. Ann Arbor: The University of Michigan Press.

Assad, M.L. 1999. Reading with Michel Serres: an encounter with time. New York: State University of New York Press.

Auzias, J-M. 1992. Michel Serres: philosophe occitan. Bordeaux: Éditions Fédérop.

Bernardis, M-A. \& Hagene, B. 1995. Mesures et démesure. Paris: Les Éditions de la Cité des Sciences et de l'Industrie.

Crahay, A. 1988. Michel Serres: La mutation du cogito. Brussels: De Boeck - Wesmael.

De Beer, C.S. 1998. Op soek na wysheid: 'n Argument ten gunste van die menswetenskappe en die moontlikheid van 'n nomadewetenskap. In Focus Forum, 6(3):33-39.

De Beer, C. S. 2010. Pragmatogony: the impact of things on humans. Phronimon, 11(2):517.

Debray, R. 1979. Lart du feu. Critique, 380:16-19.

D’Espagnat, B. 1990. Penser la science, ou les enjeux du savoir. Paris: Bordas.

Felman, S. 1979. De la nature des choses ou de I'ecart a I'equilibre. Critique, 380:315.

Kurzweil, R. 1999. The age of spiritual machines: when computers exceed buman intelligence. Oxford: Oxford University Press.

Latour, B. 1987. The enlightenment without the critique: A word on Michel Serres' philosophy, in Contemporary French Philosophy, edited by A. Phillips Griffiths. Cambridge: Cambridge University Press.

Lévy, P. 1997. Collective intelligence. New York: Plenum Trade.

Lyotard, J-F. 1988. Peregrinations: law, form, event. New York: Columbia University Press.

Mandelbrot, B.B. 1982. The fractal geometry of nature. San Francisco: Freeman.

Mason, H.O. 1990. What is an information professional. journal of education for library and information science, 31 (2):122-138.

Merleau-Ponty, M. 1969. La prose du monde. Paris: Gallimard.

Peitgen, H.O. \& Richter, P.H. 1986. The beauty of fractals. Berlin: Springer Verlag. 
Pierssens, M. 1979. Le souffle de mille ouragans. Critique, 380:102-112.

Prigogine, I. \& Stengers, I. 1989 Tussen tijd en eeuwigheid: de nieuwe plaats van de mens in de natuurwetenschap. Amsterdam: Uitgeverij Bert Bakker.

Salomon, J- J.; Sagasti, F R.; Sachs- Jeantet, C. 1994 The uncertain quest: science, technology, and development. New York: United Nations University Press.

Serres, M. 1968. Hermès I: La communication. Paris: Minuit.

Serres, M. 1972. Hermès II: L'Interférence. Paris: Minuit.

Serres, M. 1974. Hermès III: La traduction. Paris: Minuit.

Serres, M. 1975. Feux et signaux de brume: Zola. Paris: Grasset.

Serres, M. 1977. Hermès IV: La distribution. Paris: Minuit.

Serres, M. 1980. Hermès V: Le passage du Nord-Ouest. Paris: Minuit.

Serres, M. 1987a. Statues. Paris: François Bourin.

Serres, M. 1987b. Hermaphrodite: Sarrasine sculpteur. Paris: Flammarion.

Serres, M. 1989a. Detachment. Athens, Ohio: Ohio University Press.

Serres, M. 1989b. Literature and the exact sciences. SubStance, 18(2):3-34.

Serres, M. 1993. Les origines de la géométrie. Paris: Flammarion.

Serres, M. 1994. Atlas. Paris: Julliard.

Serres, M. 1995a. Angels: A modern myth. Paris/New York: Flammarion.

Serres, M. 1995b. Genesis. Ann Arbor: The University of Michigan Press.

Serres, M. 1995c. The natural contract. Ann Arbor: University of Michigan Press.

Serres, M. 1995d. Conversations on science, culture, and time. Ann Arbor: The University of Michigan Press.

Serres, M. 1997. The troubadour of knowledge. Ann Arbor: The University of Michigan Press.

Serres, M. 1999. Variations sur le corps. Paris: Le Pommier-Fayard.

Serres, M. 2007. The parasite. Minneapolis: University of Minnesota Press.

Serres, M. 2008. The five senses: a philosophy of mingled bodies. London: Continuum

Serres, M. 2009a. Ecrivains, savants et philosophes font le tour du monde. Paris: Le Pommier.

Serres, M. 2009b. Temps des crises. Paris: Le Pommier.

Stengers, I. 2013. Une autre science est possible! Paris: La Découverte. 